\title{
Integrated Geophysical Mapping of Near-surface Structures and Utilities in Ile-Ife, Nigeria
}

\author{
Akindulureni John Olaolu*", Adepelumi Adekunle Abraham, Ebiko Olatunde \\ Department of Geology, Obafemi Awolowo University, Nigeria \\ *Corresponding Author: akindulureni@hotmail.com
}

Copyright (C) 2015 by authors, all rights reserved. Authors agree that this article remains permanently open access under the terms of the Creative Commons Attribution License 4.0 International License

\begin{abstract}
Magnetic, self-potential (SP) and Ground-penetrating radar (GPR) methods were employed to investigate the near-surface conditions beneath a road in Obafemi Awolowo University Campus, Ile-Ife with the aim of mapping previously suspected dyke, fractures, buried utilities in the area. Fifty stations were established for the magnetic and SP methods along five and four traverses respectively while GPR data was acquired along three traverses, all parallel to the general strike of the rocks in the area (NW-SE). The magnetic and SP readings obtained were interpreted qualitatively and quantitatively using least-squares to identify the location/trends and determine source parameters of features of interest. Also, GPR sections were analyzed using basic radar processing tools. The magnetic field readings ranged from $-310 \mathrm{nT}$ to $220 \mathrm{nT}$ while the SP readings with range $-126 \mathrm{mV}$ to $55 \mathrm{mV}$. The anomaly source was delineated on low closures on the iso-magnetic map while the inflexion points on the SP profiles lie above the target source. Results of quantitative interpretation of magnetic and SP anomalies revealed a spherical, sub-vertical source with depth to top values of $1.6 \mathrm{~m}$ to $3.85 \mathrm{~m}$. The radargrams revealed the positions and depths of utilities such as pipes and cables, shallow-dipping fractures, a road culvert and partially weathered bedrock layers overlying fresh basement in the area. The penetration depth of the GPR was $14 \mathrm{~m}$ and the depth to top of the basement ranged from $4 \mathrm{~m}$ to $6 \mathrm{~m}$. The techniques employed mapped the subsurface structural/cultural features in the study area and determined their positions and depth extents.
\end{abstract}

Keywords Self-potential (SP), Ground-penetrating radar (GPR), Dyke, Fractures, Utilities

\section{Introduction}

The knowledge of the earth, its composition and the materials it contains has been furnished by investigations into both shallow and deep inaccessible parts of the crust, mantle and core. These investigations have aided the understanding of the earth's history, the behavior of its dynamic landforms and the characteristics of its different parts. However, since the advent of civilization, mankind has interacted more with the near-surface part of the Earth's crust than the other deeper layers. As a result increased understanding of the dynamics of this part of the Earth is paramount [1].

In this paper, the primary aim was to map the shallow portions of the earth within a defined area in Ile-Ife; up to a depth of about $15 \mathrm{~m}$, and confirm the presence of previously suspected fractures, fault, dyke and man-made utilities. Three geophysical methods namely Magnetic, Self-potential (SP) and Ground Penetrating Radar (GPR) were employed in the present study.

The magnetic method involves the measurement of variations in total magnetic field of the earth, caused by local differences in the magnetization of the subsurface rocks and soils. It has a wide range of applications and has been used in locating buried metalliferous man-made objects such as cables and pipelines, location of boundaries between rocks, faults, and dykes [2]. The SP method is a passive geophysical technique that responds to naturally-occurring potential differences generated mainly by electrochemical, electrokinetic, and thermoelectric sources in the subsurface and has many applications ranging from mineral exploration, hydrogeological, environmental, geotechnical and engineering investigations. There is recorded success in the use of the SP method in shallow subsurface mapping of simple geometrical bodies [3] and sheet-like bodies [4].

The GPR technique (which is a novel technique in Nigeria) detects electrical discontinuities due to features such as bedding planes, fault planes etc. in the shallow subsurface (usually less than $50 \mathrm{~m}$ ) by the generation, transmission, propagation, reflection and reception of discrete pulses of high-frequency electromagnetic energy with high-resolution imagery [5]. GPR is effective for subsurface fracture and fracture zone imaging [6], soil and rock stratigraphy mapping [7] and underground utility mapping [8]. Consequently, this integrated study was done to verify the presence of the geologic structures and cultural utilities in the area, and also to demonstrate the efficacy of the GPR technique in shallow subsurface mapping in a basement complex terrain of southwestern Nigeria.

\section{Study Location and Geologic Setting}

Nigeria, which lies close to the equator within latitudes $4^{\circ}$ $\mathrm{N}$ and $14^{\circ} \mathrm{N}$ and longitudes $3^{\circ}$ and $15^{\circ} \mathrm{E}$, is comprised of 
Precambrian basement rocks and sedimentary basins (Figure 1). The basement rocks lie in the north-central and southwestern parts of the country. The lithologic groups that make up the Nigerian basement complex have been extensively described by various authors, such as Oyawoye [9], Rahaman [10,11], Odeyemi [12], McCurry [13] and a host of others. According to [11], the Nigerian basement complex consists of six major groups, vis: (i) the migmatite-gneiss-quartzite complex (ii) the metasedimentary and meta-igneous rocks (iii) charnockitic, gabbroic and dioritic rocks (iv) the Older Granites (v) calc-alkaline volcanics and hypabyssal rocks (vi) the basic and syenite dykes.

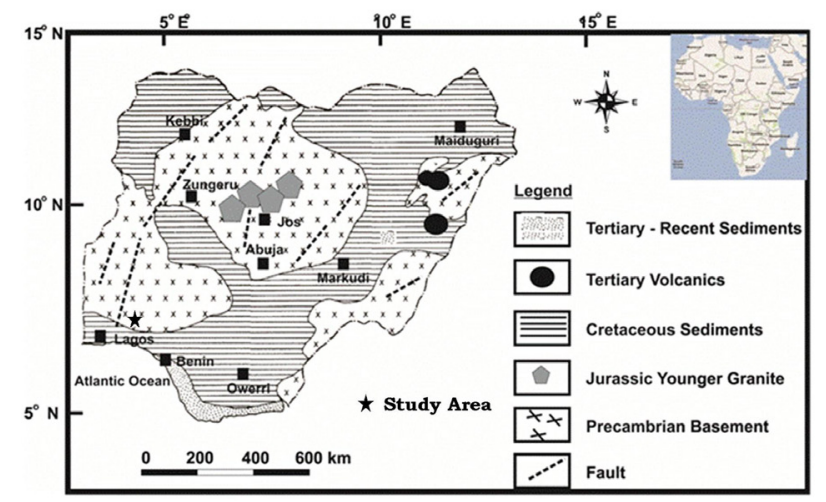

Figure 1. Generalized geological map of Nigeria showing the study area and trace of equatorial fracture zones. (Modified after [1]).

The study was carried out along Adesoji Aderemi road (Road 1) in Obafemi Awolowo University campus. The campus is situated in the northwestern outskirts of Ile-Ife, Osun state, Southwest Nigeria. It is located within latitudes $07^{\circ} 30.5^{\prime} \mathrm{N}$ and $07^{\circ} 34^{\prime} \mathrm{N}$ and longitudes $04^{\circ} 30.5^{\prime} \mathrm{E}$ and $04^{\circ}$ 32 ' $\mathrm{E}$. The area is underlain by rocks of the Ife-Ilesha schist belt, which is predominantly a migmatite-gneiss-quartzite complex. The major petrologic units peculiar to the study area are grey gneiss, granite gneiss and mica schist (Figure 2), however minor amphibolite, dolerite dykes, vein quartz and pegmatite outcrops occur in places. The grey gneiss (which derives its name from its grey coloration) occurs very close to the pink granite gneiss and is separated in places by narrows strip of mica schist. The texture of this variety of gneiss is fine to medium grained with well-developed foliation defined by preferred orientation of biotite. This rock is mostly composed of quartz, biotite, plagioclase, $\mathrm{K}$-feldspar and hornblende. The granite gneiss is defined by mafic (biotite rich) and felsic (quartz and feldspars) mineral bands which depict the foliation. The texture varies from medium grained to very coarse, almost becoming pegmatitic in places. Augen structures are commonly observed with wide and narrow quartz veins commonly seen on the rock [14]. On outcrop scale, the granite gneiss is composed of biotite, k-feldspar, quartz and garnet. The mica schist with fine to medium grain sizes contains high proportion of muscovite and biotite in relatively equal proportion, with minor occurrence of k-feldspars, plagioclase and quartz. The geologic framework of Obafemi Awolowo University has been exhaustively studied and discussed by Adepelumi et al. [15].

The two major fault zones in the area are characterized by near symmetry magnetic anomalies. The magnetic profiles show background anomaly that ranges between 1090 and 1200 gamma. The magnetic properties along the fault zone may be indicative of weak mineralization [16]. The two major discernable linear magnetic anomalies that characterized the central part of the investigated area correlate with the fundamental northeasterly-southwesterly structural alignment of the Precambrian basement rocks in southwestern Nigeria deduced by Odeyemi [17] and Ajibade et al. [18]. The magnetic anomalies pattern displayed along this structure possibly suggest shallow basement depth, and basement controlled strike-slip fault in the region.

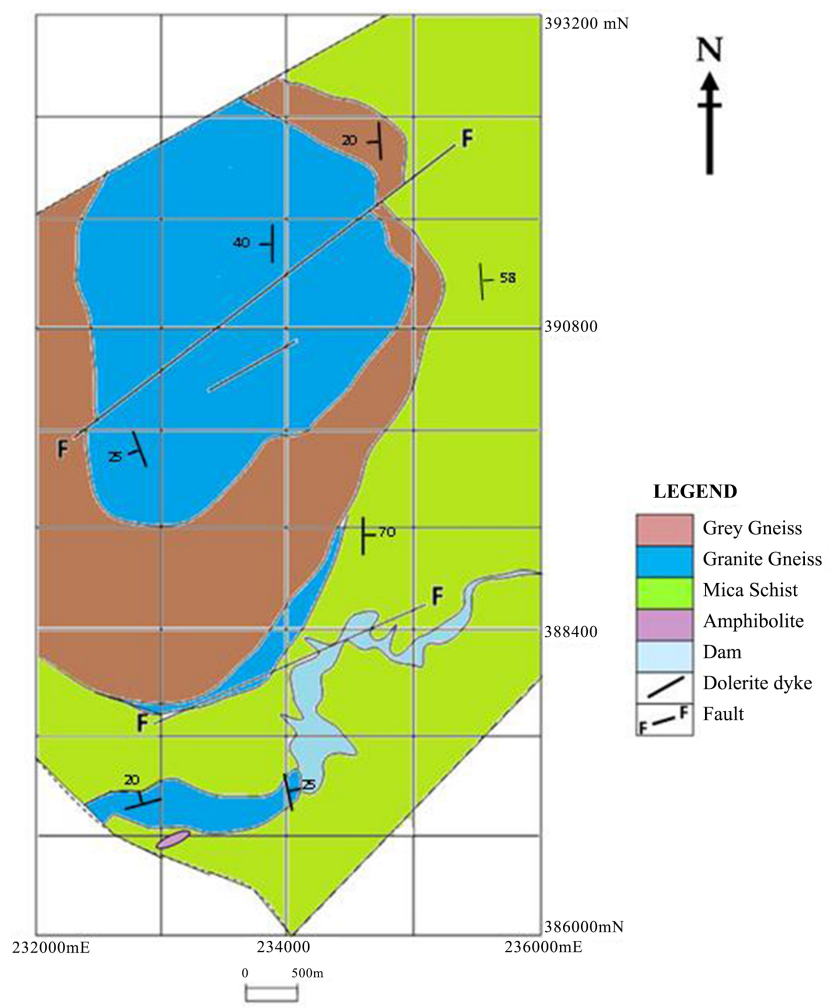

Figure 2. Generalized geological map of Obafemi Awolowo University Campus showing the petrologic groups that characterize the Precambrian Basement (Modified after [15]).

\section{Methodology}

Three geophysical methods were employed for the subsurface structural and utilities mapping in the area; Magnetic, Electrical (SP) and Electromagnetic (GPR) methods. All the traverses established for the three methods were run parallel to the general strike (NW-SE) of the rocks in the area. The survey design used in the study is presented in Figure 3. 


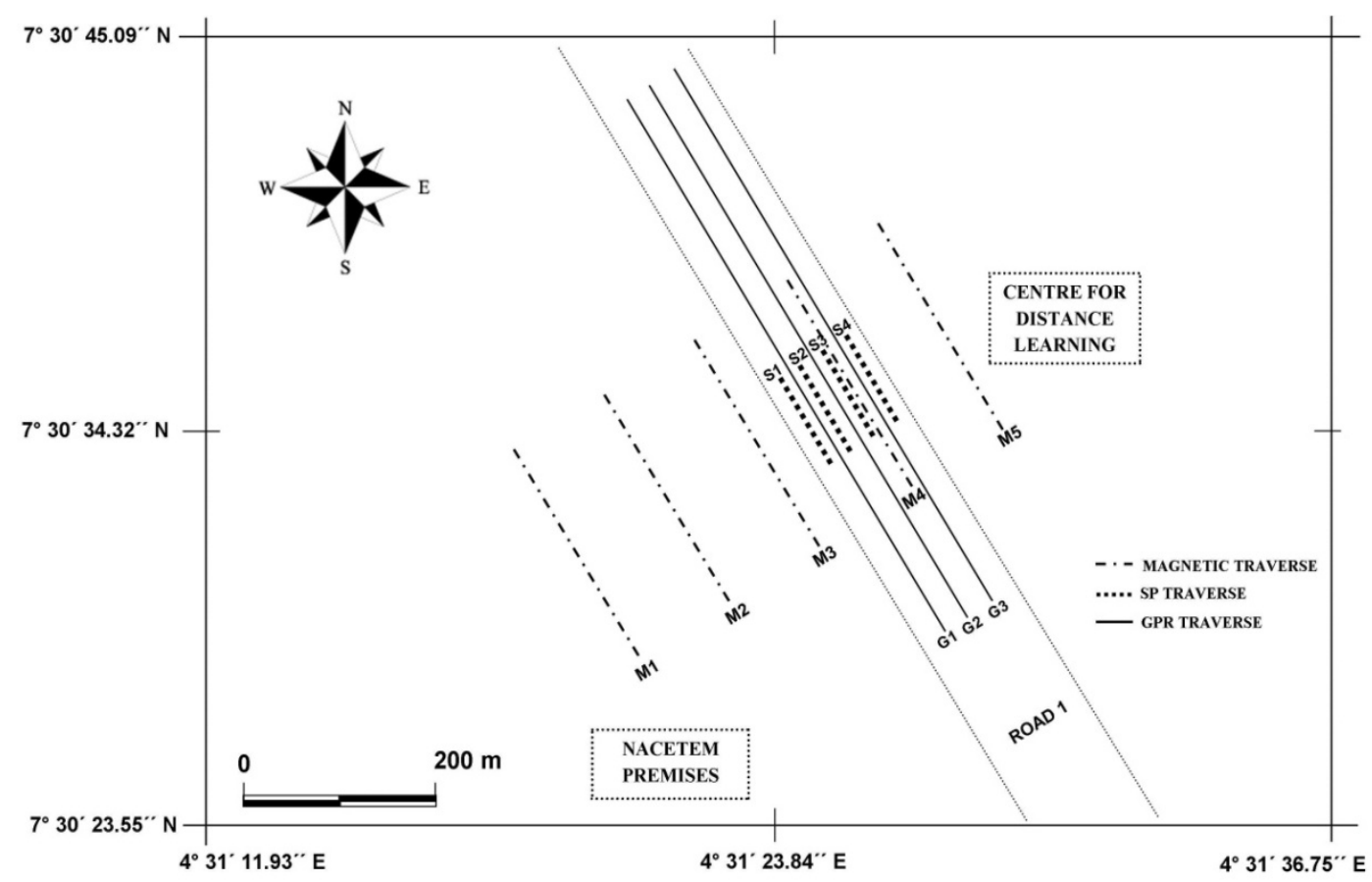

Figure 3. Field data acquisition layout

\subsection{Ground Magnetic Survey}

The Geometric proton precession magnetometer, which measures the absolute value of the total magnetic field strength, was employed for the magnetic measurements on fifty (50) stations along five parallel $250 \mathrm{~m}$ long traverses, $100 \mathrm{~m}$ apart (trending $140^{\circ}$ ). The methodology used by Adepelumi et al. [19] was adopted for the magnetic data processing. The magnetic measurements loop were closed by establishing base measurement points outside each traverse; repeat magnetic readings were taken at these points before and after measurements were made on the traverses (Figure 3). This was done with the purpose of carrying out drift and/or diurnal corrections on the magnetic data recorded. The observed diurnal variation was removed from our data from the observed drift in the magnetic reading. Three repeat magnetic readings and time observation were recorded at 5 $\mathrm{m}$ intervals along each traverse. Thus, in order to remove magnetic noise and diurnal magnetic variation from the data obtained, the magnetic data were filtered using a three point moving technique $[20,21]$. Noise due to secular change or epoch was considered very negligible because the measurement time was less than two hours for each traverse. After the diurnal correction and filtering were carried out, the next stage of reduction was to calculate the anomalous geomagnetic field. The Earth's normal magnetic field was calculated through IGRF (the known regional geomagnetic field of 32,000 $\mathrm{nT}$ for the investigated area) and subtracted from the diurnal-corrected observed value to produce the residual geomagnetic field. The corrected geomagnetic field data are presented as profiles (Fig. 5). The reduced geomagnetic field data were plotted on the vertical axis, and the station position on the horizontal axis.

\subsection{Self-potential (SP)}

The self-potential readings were taken using the Syscal Junior Terrameter along four traverses, with length of $100 \mathrm{~m}$ and traverse-traverse separation of $10 \mathrm{~m}$. A total of fifty (50) stations were occupied with station-station spacing of $2 \mathrm{~m}$. The fixed base (total field) array was employed and the acquired data was processed by stacking ten readings at each of the measurement points.

\subsection{Ground Penetrating Radar (GPR)}

The fundamental theoretical background of the GPR technique has been exhaustively described by various authors, including Neal [5], Davis and Annan [7] and Conyers and Goodman [22].

The survey was carried out using the GSSI SIR-2000 system, along three traverses (azimuth $140^{\circ}$ ). Each traverse was $600 \mathrm{~m}$ long, with traverse-traverse separation of $10 \mathrm{~m}$. The SIR-2000 was coupled to a $200 \mathrm{MHz}$ shielded antenna. The antenna was housed in a single module with no means of varying antenna separation (monostatic antennae) and oriented parallel to the survey direction (parallel-broadside).

The following acquisition parameters were used for the GPR survey; Data Collection Mode: Continuous, Range: 300ns, Samples per Scan: 1024, Resolution: 16 bits, Number of gain points: 5, Vertical High Pass Filter: $30 \mathrm{MHz}$, Vertical Low Pass Filter: $400 \mathrm{MHz}$, Scans per second: 32, Horizontal Smoothing: 5 scans, Transmit Rate: $64 \mathrm{KHz}$.

During data processing, the return centre frequency was estimated for the three traverses and it ranged from $180 \mathrm{MHz}$ to $195 \mathrm{MHz}$. Standard data processing techniques were applied to the acquired radargrams (Figure 4). These include data editing (which involves data reorganization, data file merging, data header background information updates, an inclusion of topography information in every file) and filtering in frequency domain by applying a band-pass filter with a centre frequency of $190 \mathrm{MHz}$ and cutoff frequencies 
(lower and higher frequency) of $150 \mathrm{MHz}$ and $250 \mathrm{MHz}$.

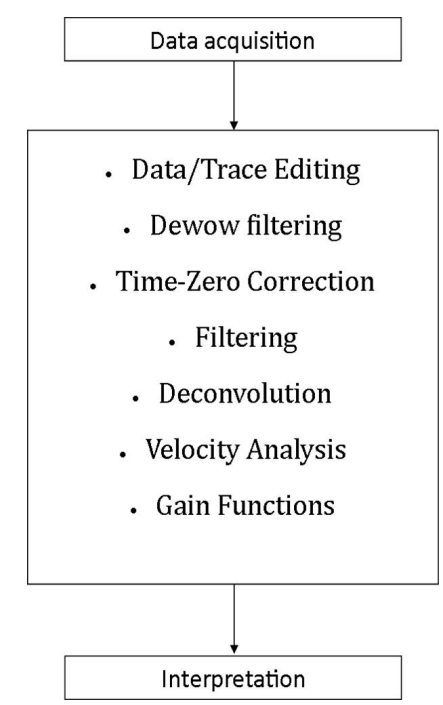

Figure 4. Processing flow sequence for the 2D monostatic, common-offset, reflection mode GPR data.

Two gain functions were applied to the data; Automatic gain functions and Custom gains. Automatic gains (AGC) increased the amplitude of the signal by a factor inversely proportional to the signal strength. AGC is more effective for recognizing low amplitude reflections [5]. The custom gain provided a constant amplitude increase for the signals irrespective of the signal strength loss.

Radar wave velocity value of $100 \mathrm{~m} \mathrm{ss}^{-1}$ obtained from the velocity spectrum analysis of the GPR sections was adopted for the time-depth conversion of the data. In addition, the processed GPR sections were subjected to amplitude and attribute analysis such as instantaneous frequency, instantaneous phase and instantaneous amplitude, with the aim of signal enhancement and improved interpretability [23].

\section{Results and Discussions}

The magnetic readings were interpreted both qualitatively as profiles (Figure 5), maps and quantitatively using least square inversion and the non-linearly constrained optimization methods. This was done by close inspection of the plotted data for approximate position of the source body. All the traverses for the magnetic intensity measurements were run in areas underlain by granite gneiss and the magnetic anomalies induced by overhead electric and communication cables and poles were identified on the magnetic profiles and duly filtered during data editing and processing.

The magnetic profiles show a background anomaly of $-85 \mathrm{nT}$ along traverse M1, -60nT along traverse M2, $-50 \mathrm{nT}$ along traverse $\mathrm{M} 3,-40 \mathrm{nT}$ along traverse M4 and $-56 \mathrm{nT}$ along traverse M5. The peak amplitude of 180nT on stations 1 to 5 along traverse M1 is due to presence of background noise from cultural features such as electrical poles and overhead cables. Also, the low magnetic field values (-320nT) recorded on station 22 along traverse M4 may indicate the presence of the target anomaly source. The approximate position, geometry and strike of the magnetic anomaly source was deduced from the closure on the iso-magnetic map (Figure 6). From the contour map of the magnetic profiles, the closures on traverse M4 showed an approximate linear body with a NE-SW trend perpendicular to the regional strike of the rocks in the area, indicating an anomaly source of dyke-like structure.

Qualitative interpretation revealed a shallow near-vertical body centred over the source with an E-W trend. Inversion of the magnetic data was performed using the Raju [24] least square inversion and the non-linearly constrained optimization method developed by Asfahani and Tlas [25] to interpret the magnetic anomalies observed along traverses 1 to 4 respectively. The inversion programs used the discrete magnetic anomaly values and the corresponding distances as input. The initial solution thus obtained was modified in an iterative process using non-linear least-squares regression by employing Marquardt's algorithm. The results obtained from the quantitative analysis of the magnetic data are shown in Table 1.

Table 1. Model Result of the Quantitative Interpretation of the Magnetic Anomalies

\begin{tabular}{|c|c|c|c|c|}
\hline Derived Magnetic Parameters & Traverse One & Traverse Two & Traverse Three & Traverse Four \\
\hline $\begin{array}{l}\text { Depth to Top (z) of the Magnetic source } \\
\qquad(\mathrm{m})\end{array}$ & 1.65 & 3.19 & 3.85 & 3.72 \\
\hline Dip Angle $(\theta)$ degrees & $19^{\circ}$ & $18^{\circ}$ & $17^{\circ}$ & $12^{\circ}$ \\
\hline Magnetic anomaly of the Source (nT) & 20 & -50 to -90 & -60 to -110 & 80 to -320 \\
\hline $\begin{array}{l}\text { RMS error (\%) between the Observed } \\
\text { and Computed Magnetic Models }\end{array}$ & 3.5 & 4.2 & 3.9 & 4.0 \\
\hline Shape of the Magnetic Source & $\begin{array}{l}\text { Spherical and } \\
\text { sub-vertical }\end{array}$ & $\begin{array}{l}\text { Spherical and } \\
\text { sub-vertical }\end{array}$ & $\begin{array}{c}\text { Spherical and } \\
\text { sub-vertical }\end{array}$ & $\begin{array}{l}\text { Spherical and } \\
\text { sub-vertical }\end{array}$ \\
\hline
\end{tabular}



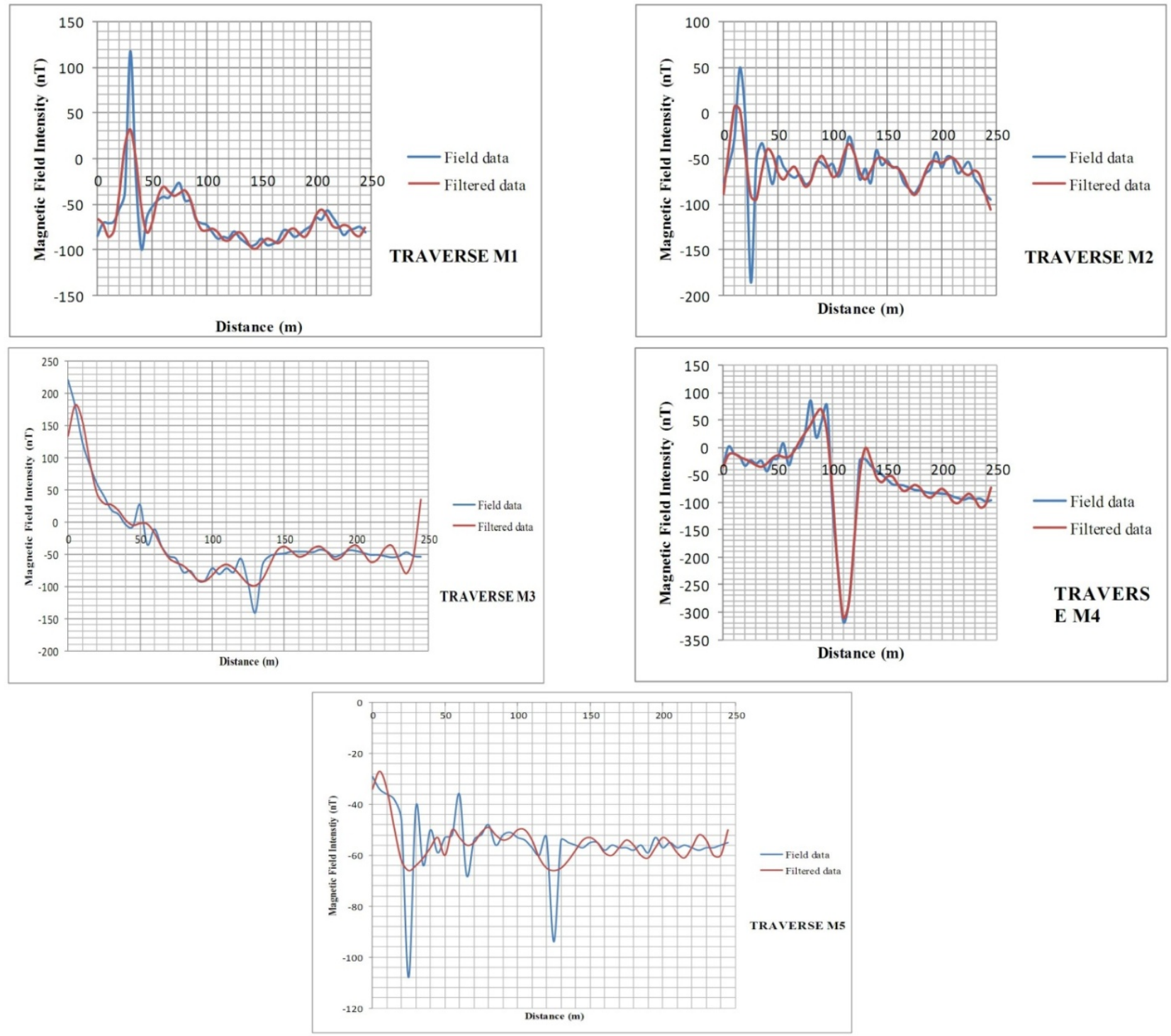

Figure 5. Profiles along the Magnetic traverses
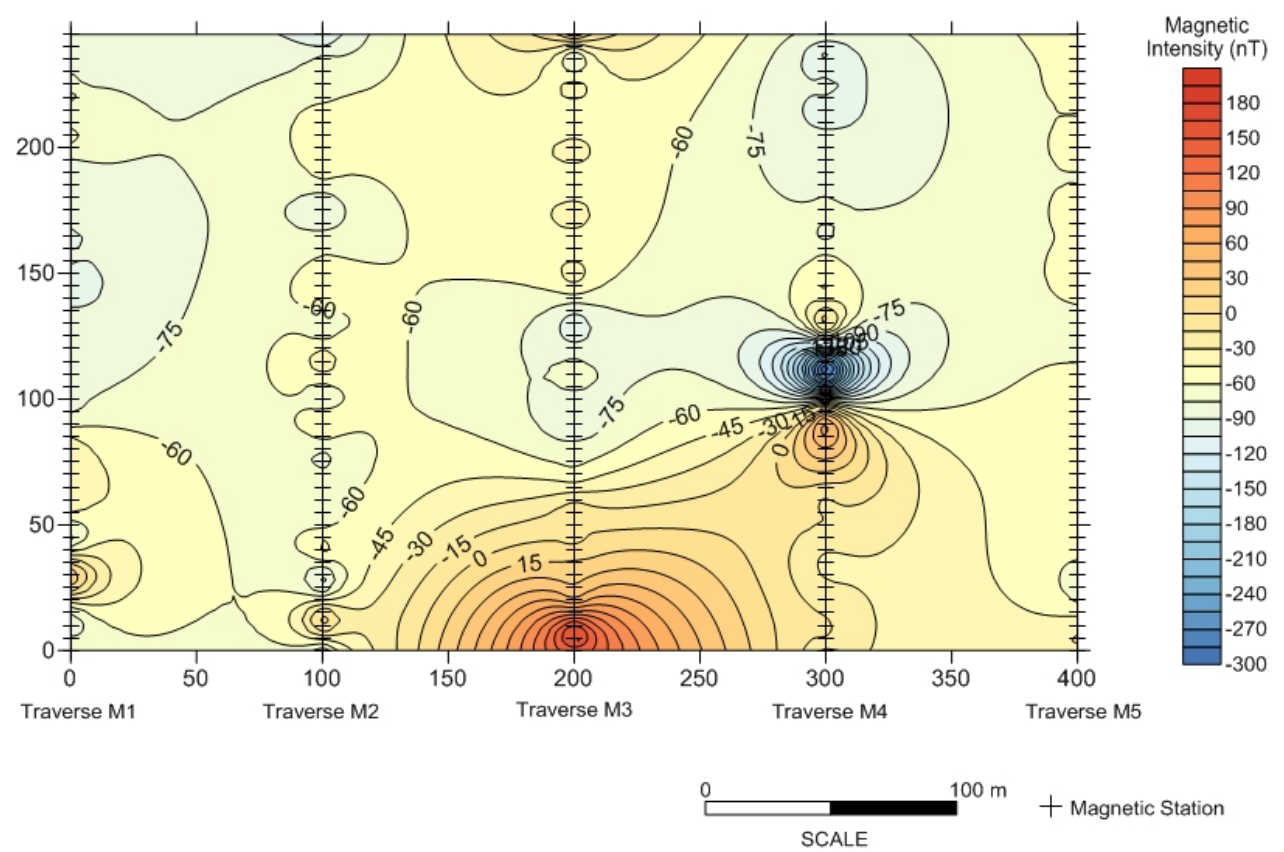

Figure 6. Iso-magnetic contour map of the study area 

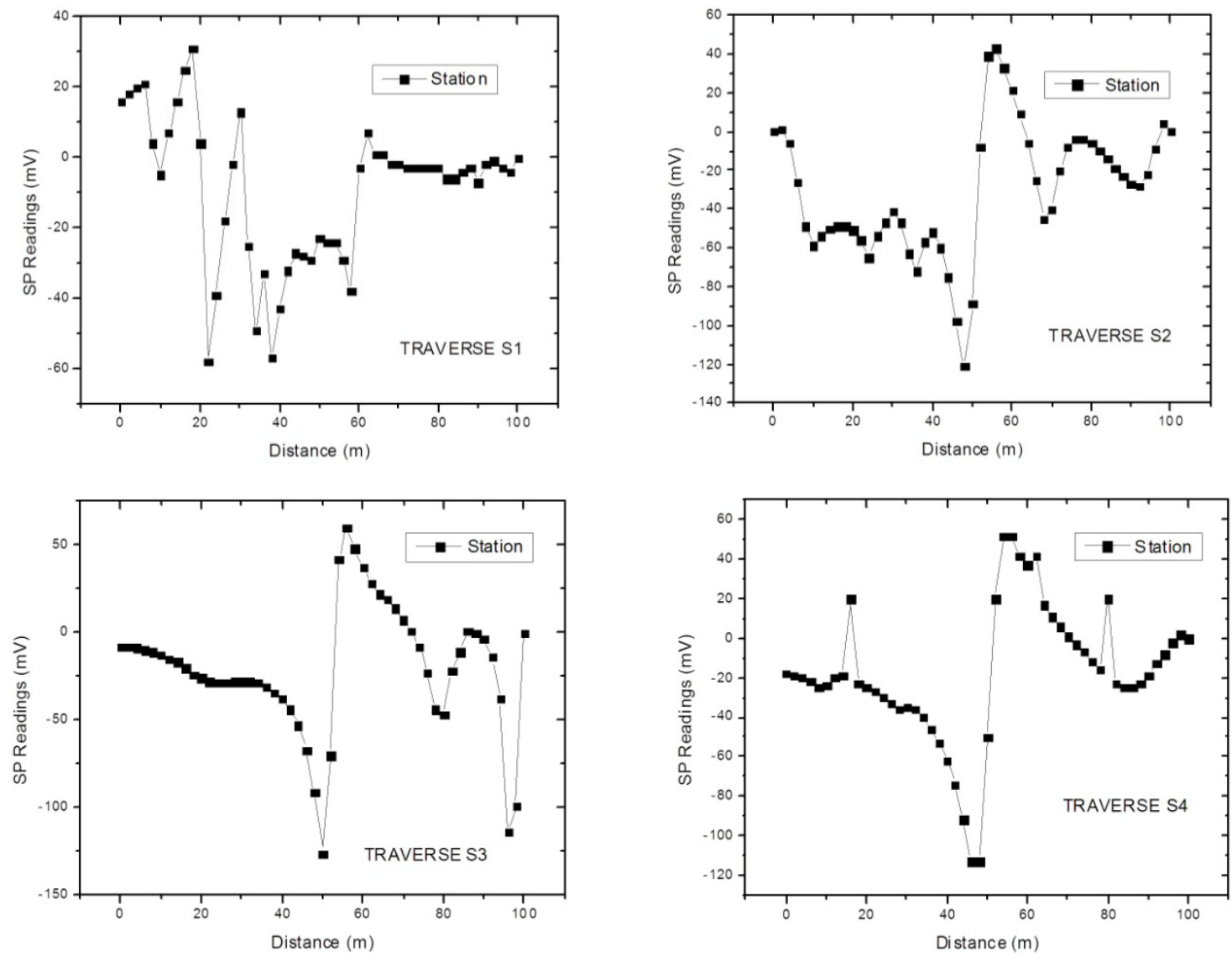

Figure 7. The SP profiles plotted for the study area

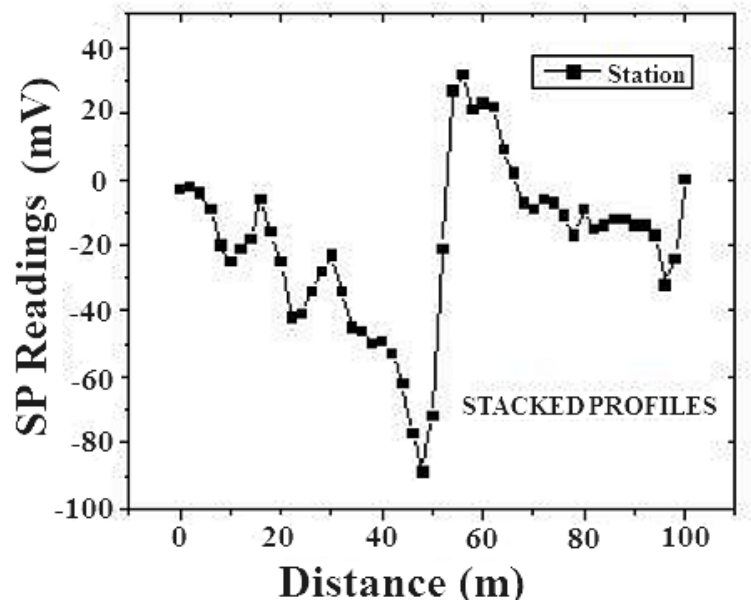

Figure 8.. Stacked profile of all the SP readings

The end result of SP survey is a set of profiles and contour maps of equipotentials. Therefore, SP data acquired along the four traverses were also interpreted qualitatively as profiles (Figure 7) and contour maps. The profiles were taken in the region of traverse M4 and were inspected for inflexion points, maximums and minimums that characteristic of anomalous bodies in the area. All the SP profiles had a relatively similar trend as shown by their semblance to the stacked profile generated (Figure 8). The minimum natural voltage value obtained was $-126 \mathrm{mV}$ and the maximum value $55 \mathrm{mV}$. The SP low on three traverses (S2, S3 and S4) was observed at stations 24 and 25 while the SP maximum occurred in stations 27 and 28. Consequently, the inflexion points on the SP traverses between stations 25 and 26 lie directly over the anomaly. On traverse S1, responses obtained on stations 1 to 17 were predominantly caused by the presence of road-side vegetation. Potentials not generated by the target source at the inflexion point constituted noise/background potentials.

An iso-voltage (SP contour) map of the four profiles was generated to identify the closures (maximum and minimums) that could suggest the presence of the anomaly (Figure 9) and this revealed a body with a linear structure straddling three traverses on the map at the stations at distance between $50 \mathrm{~m}$ and $54 \mathrm{~m}$. This signature suggests the presence of the anomaly source body in the area.

Combined inspection of the magnetic and SP closures on the contour maps for the magnetic highs lows and SP inflexion points on traverses M4, S2, S3 and S4 revealed the presence of an NE-SW trending anomalous body of linear structure, interpreted as the suspected dyke.

Quantitative interpretation of the SP anomalies was carried out using the least-squares minimization algorithm developed by Abdelrahman [26] and El-Araby [27] to determine the shape of the buried and compute the nature of source geometry polarized target from self-potential (SP) anomaly. In the approach adopted, the model parameters that give a best fit were derived using an initial presumption, as well as characteristic points and distances from the measured anomaly curve. The root mean square (RMS) of the derived model was also calculated. From the inversion studies, it is evident that the SP anomaly obtained is due to a spherical and sub-vertical polarize source. The determined model parameters are shape, depth $(\mathrm{z})$, polarization angle $(\theta)$ and RMS error. The obtained results are shown in Table 2 . 


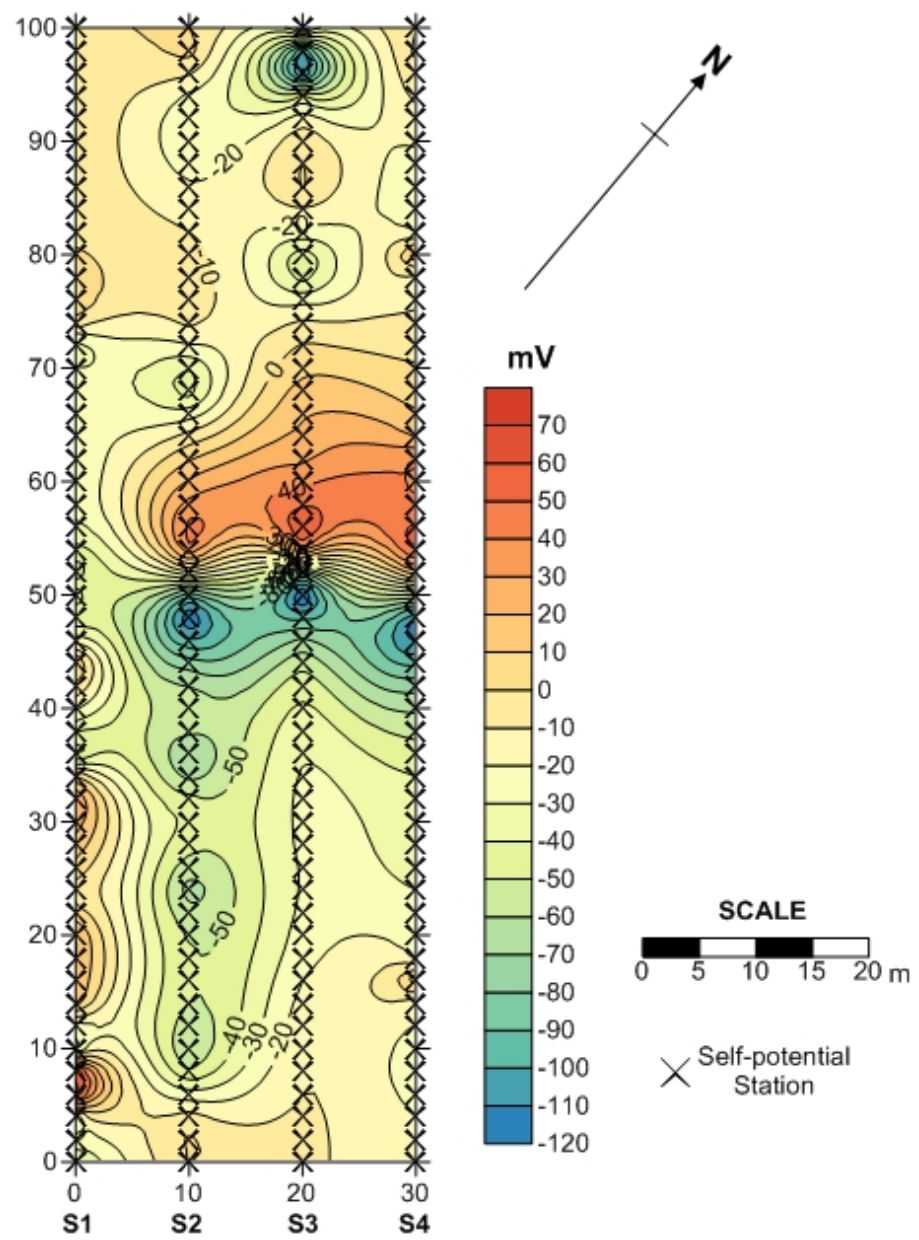

Figure 9. Iso-voltage (SP contour) map of the study area

Table 2. Model Result of the Quantitative Interpretation of the SP Anomalies

\begin{tabular}{|c|c|c|c|c|}
\hline Derived SP Parameters & Traverse One & Traverse Two & Traverse Three & Traverse Four \\
\hline Depth to Top(z) of the SP Source (m) & 1.6 & 3.0 & 3.6 & 3.5 \\
\hline Polarization angle $(\theta)$ degrees & $17^{\circ}$ & $16^{\circ}$ & $16^{\circ}$ & $10^{\circ}$ \\
\hline SP Anomaly of the Source (mV) & 20 & 70 & 60 & 60 \\
\hline $\begin{array}{l}\text { RMS error (\%) between the Observed } \\
\text { and the Computed SP Models }\end{array}$ & 2.1 & 2.7 & 2.4 & 2.5 \\
\hline Shape of the SP Source & $\begin{array}{l}\text { Spherical and } \\
\text { sub-vertical }\end{array}$ & $\begin{array}{l}\text { Spherical and } \\
\text { sub-vertical }\end{array}$ & $\begin{array}{c}\text { Spherical and } \\
\text { sub-vertical }\end{array}$ & $\begin{array}{c}\text { Spherical and } \\
\text { sub-vertical }\end{array}$ \\
\hline
\end{tabular}

It is evident from this study that the SP model results are in good correlation with the magnetics models. This result further provides insight into the nature of the source body at depth. Also, it is noticed that the RMS errors obtained from this study are generally less 5\% using the two techniques (SP and Magnetics). This possibly attests to the accuracy of the least square inversion technique used.

The interpretation of the GPR data was done in terms of features identification, primarily accomplished by examining the reflection characteristics (e.g., continuous line, hyperbola, or multiple discontinuous chaotic reflections) of the processed radar sections. Using the antenna frequency of 200 $\mathrm{MHz}$, the GSSI equipment was able to image up to a depth of $14 \mathrm{~m}$ in the area.

The interpretation was done with the knowledge of the local geology and the presence of buried utilities in the area. The depth to the top of the basement complex rocks as observed on the GPR sections varied from $4 \mathrm{~m}$ to $6 \mathrm{~m}$ in agreement with earlier studies carried out by Olorunfemi and Okhue [28]. An attempt to determine the road pavement thickness from the analysis of the GPR data gave a of $20 \mathrm{~cm}$, however, the $200 \mathrm{MHz}$ antenna used in the survey was unable to accurately determine the engineering properties of the road as would antennas of higher frequencies.

From the interpretation of the radar sections along the three traverses, buried utilities such as pipes and cables were discovered. A culvert that exists beneath the road was also successfully mapped (Figure 10), along with geologic structures such as shallow dipping fractures. Regions beneath the road that are incompetent and susceptible to failure were highlighted in the radar sections. Furthermore, partially weathered bedrock layers overlying fresh basement characterized by high amplitude (as a result of increased moisture content) were distinguished on the radargram 
(Figure 11). The thickness of the weathered layer varied from $1 \mathrm{~m}$ to $4 \mathrm{~m}$ in the study area.

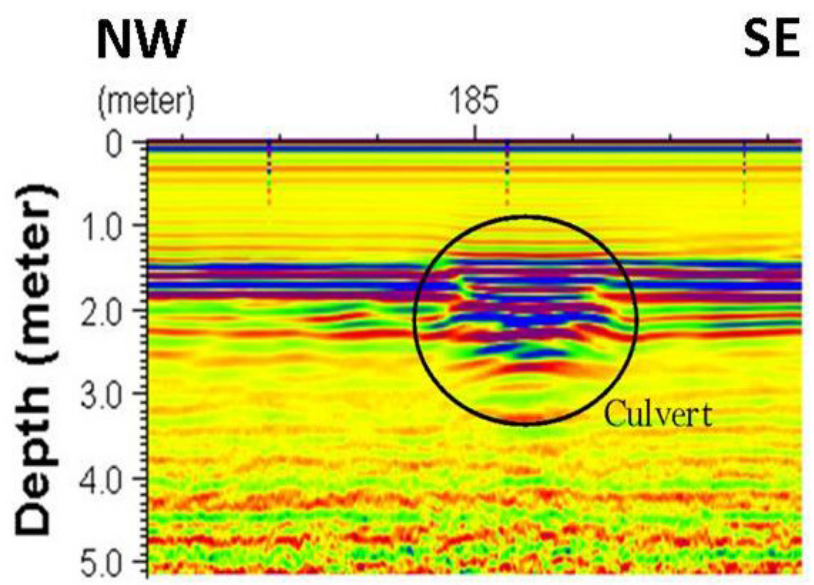

Figure 10. Road culvert reflection on the radargram

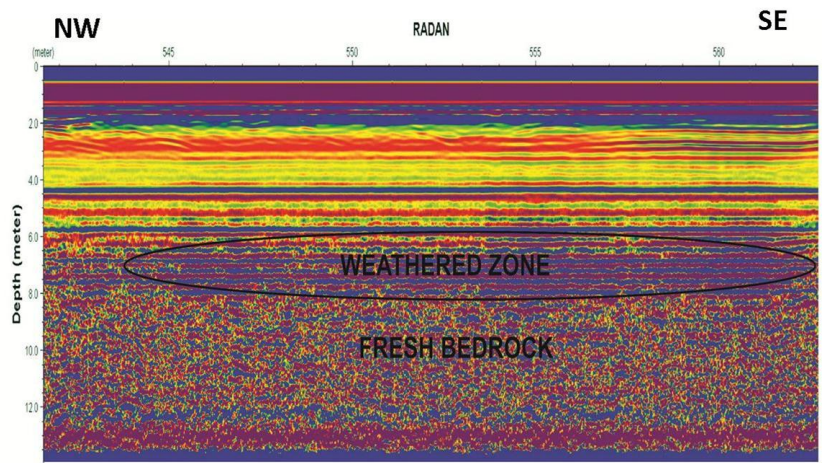

Figure 11. Zone of intense weathering characterized by increased amplitude in EM wave energy
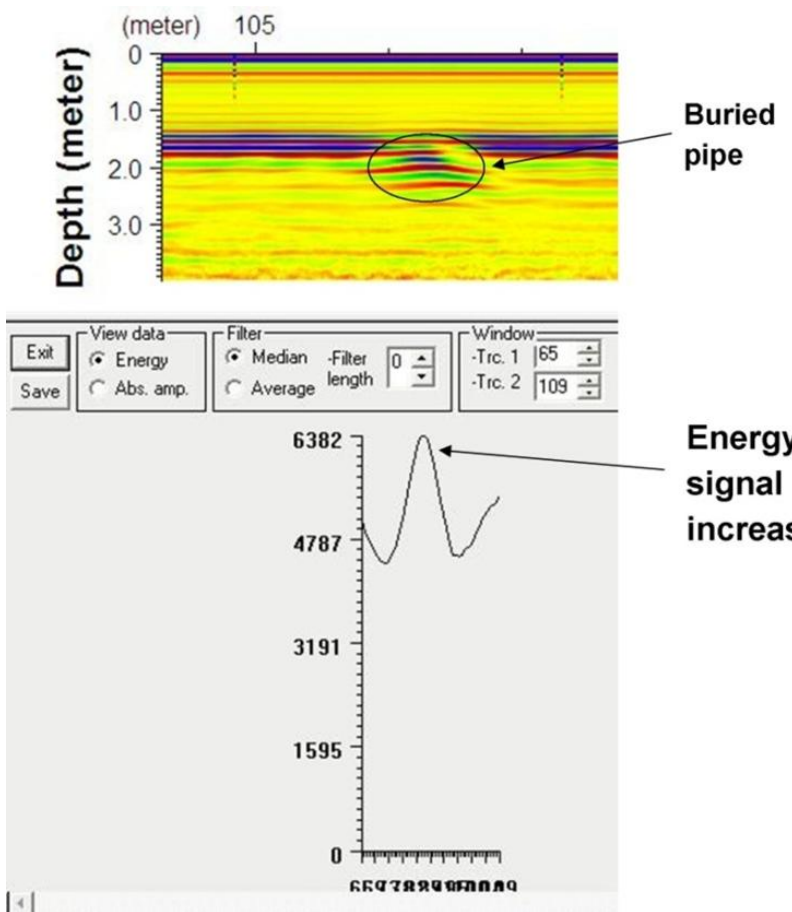

Energy signal increase

Figure 12. Characteristic response obtained in region of pipes and electrical cables along the traverses.

Diffraction hyperbolas characteristic of subsurface utilities (pipes, cables) were represented on the radargrams at different points on the traverse at depths of $0.5 \mathrm{~m}$ to $3 \mathrm{~m}$. The top of the hyperbolic reflections from the utilities marked the top of the pipes and cables. The pipes and cables mapped along the traverses were $20 \mathrm{~cm}$ to $50 \mathrm{~cm}$ wide (Figure 12) and a subsurface model of the pipe region pipe is shown in Figure 13. Surface expressions of the pipes and cables were seen in the study area and the diameters of these utilities correspond with those obtained from the analysis and interpretation of the radargrams. The pipes are the main channels for the water and University's sewage disposal system, while the cables serve as the passageways for electrical conduits.
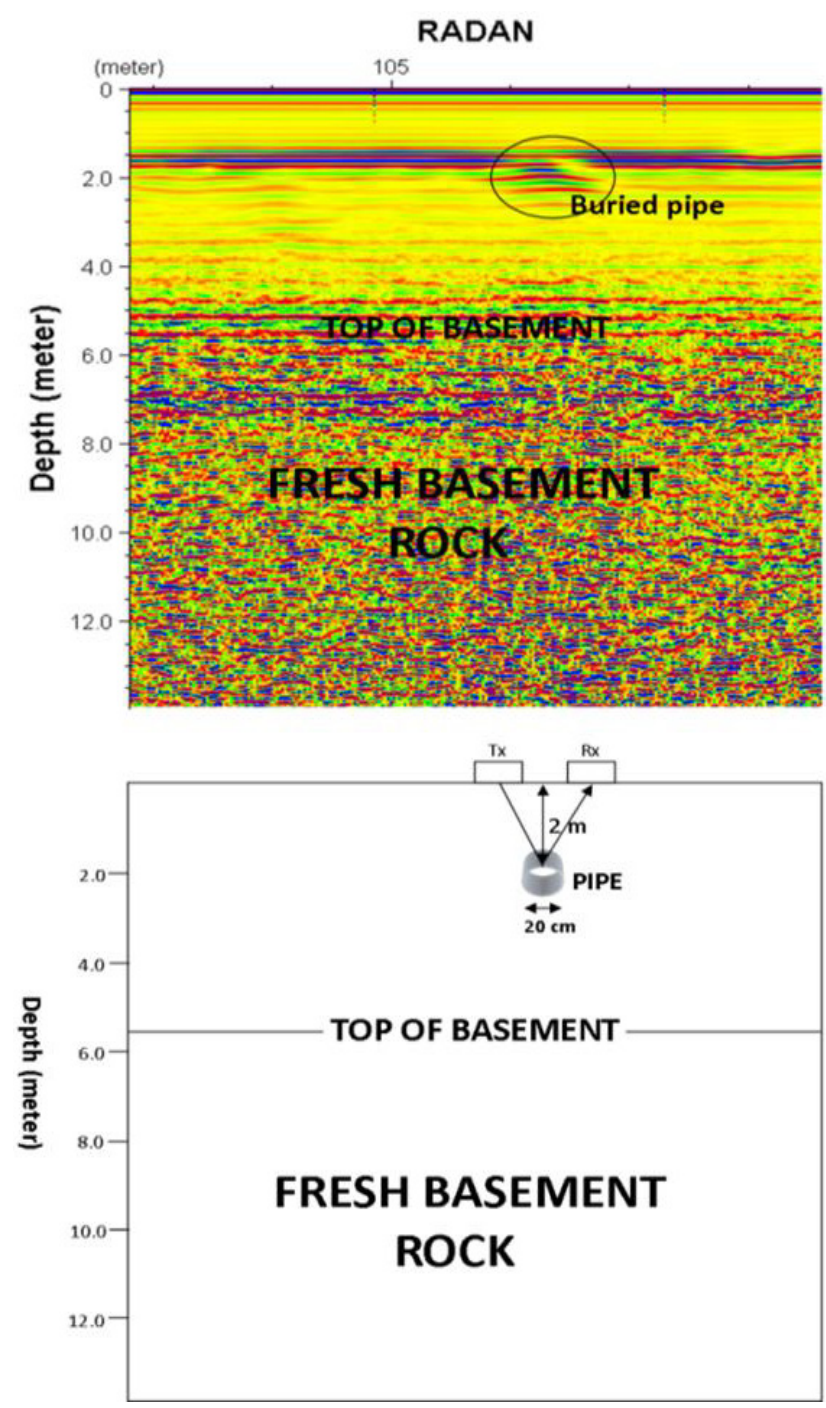

Figure 13. Underground pipe at depth of $2 \mathrm{~m}$, approximately $20 \mathrm{~cm}$ in width.

\section{SE}

(meter) 50

NW

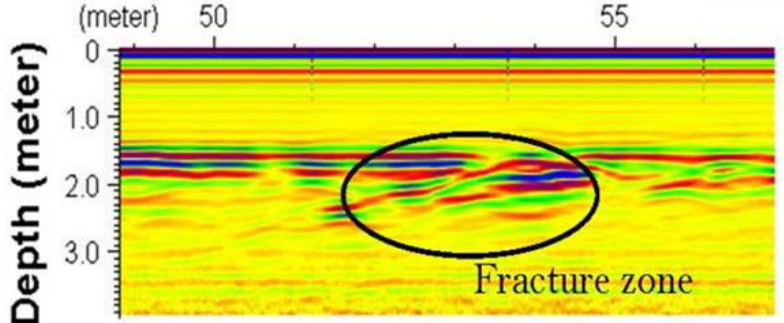

Figure 14. Joint dipping at $20^{\circ} \mathrm{SE}$ 
The fractures observed on the sections are mainly sub-parallel shallow-dipping joints, with average dip of $20^{\circ} \mathrm{SE}$ (Figure 14). The analysis of the energy of the EM wave around the joints gave high amplitude in the region of the joints due to high reflectivity caused by the subsurface discontinuity and the properties of the materials infilling the fractures. The presence of a minor fault with an approximate $80 \mathrm{~cm}$ displacement was also mapped in the bedrock (Figure 15) while the fault signal on the radar section was processed with Hilbert transform using the Instantaneous amplitude. Envelope (instantaneous amplitude) calculates the absolute value of each wavelet by converting negative wavelets to positive wavelets, resulting in a positive mono-pulse wavelet. This process is used to emphasize the true resolution of the data, and can be used to simplify data and evaluate the signal strength and reflectivity. To this end, the envelope display is extremely useful for depicting the spatial resolution of the data [29]. Furthermore, wave energy amplitude analysis was carried out on the radargram in the region of the fault and it gave a sharp spike in the energy absorption by the fault zone (Figure 16).
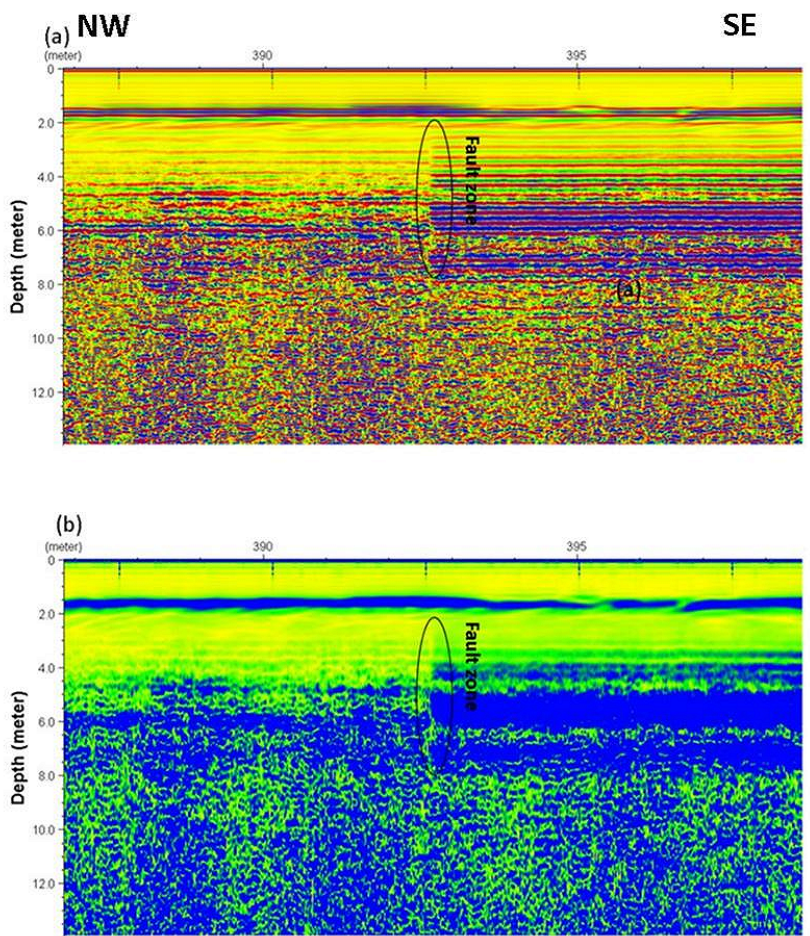

Figure 15. Fault zone mapped along GPR traverse 2 (a) Processed radargram before application of Hilbert Transform (b) Processed radargram after application of instantaneous amplitude

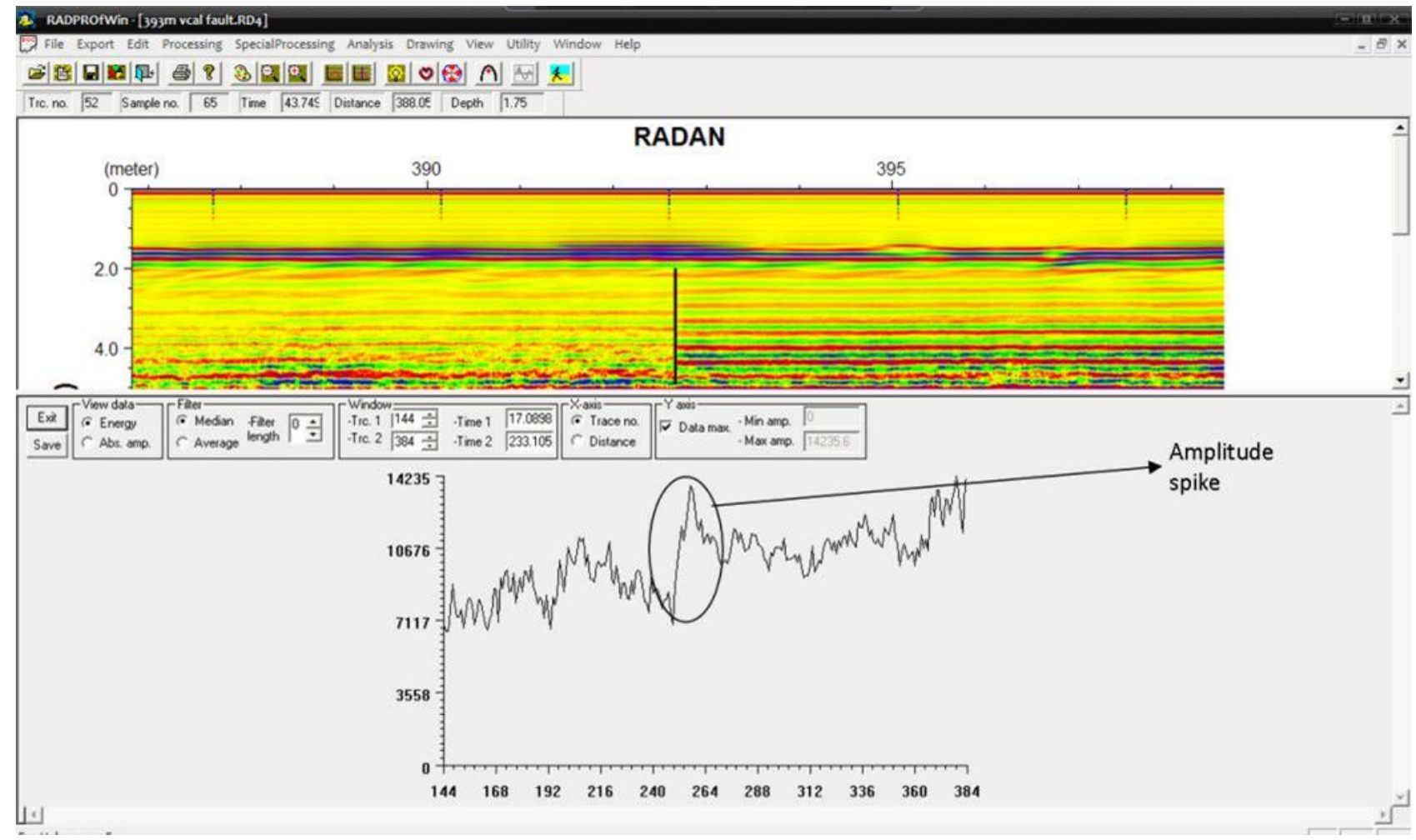

Figure 16. Amplitude analysis of EM wave energy in the region of the fault. 


\section{Conclusions}

The integration of three geophysical techniques for shallow subsurface structural and utilities mapping has been successfully applied in the present study. Qualitative and quantitative interpretation of magnetic and SP data was done to ascertain the location, trend, shape and depth to the top of a suspected anomalous body believed to be a dyke in the granite gneiss host. Qualitative interpretation of magnetic and SP profiles and maps revealed a linear body with NE-SW trend, perpendicular to the general strike direction of the rocks in the area. The results obtained from the quantitative interpretation of the magnetic and SP anomalies showed that the source has a spherical shape and sub-vertical orientation and the depth to the top of the anomaly were in agreement (Magnetics; 1.65m-3.85m and SP; 1.6m-3.6m). In addition, underground pipes and cables, fractures, road culvert, weathered and fresh bedrock layers were mapped by the GPR waves to a signal penetration depth of $14 \mathrm{~m}$. The depth to top of the Precambrian basement interpreted using time-depth conversion value of $100 \mathrm{~m}^{-1}$ obtained from GPR velocity spectrum analysis varied from $4 \mathrm{~m}$ to $6 \mathrm{~m}$ beneath the traverses, in agreement with previous studies carried out in the area. Surface expression of the utilities (pipes and cables) in the area had a maximum diameter of $50 \mathrm{~cm}$ in correlation with the results obtained from the radar sections. Furthermore, the fractures (shallow-dipping joints and fault) mapped extended into the bedrock. Summarily, traces of the dyke anomaly that was successfully mapped by the magnetic and SP methods were distinguished on the radar sections.

\section{Acknowledgements}

The authors are thankful to KIGAM, South Korea especially Dr. Jung-Ho Kim, for the provision of the GPR processing and interpretation software RADPRO ${ }^{\circledR}$.

\section{REFERENCES}

[1] Adepelumi, A. A., and O. Fayemi (2012): Joint application of ground penetrating radar and electrical resistivity measurements for characterization of subsurface stratigraphy in Southwestern Nigeria. Journal of Geophysics and Engineering, 9, 397-412, doi: 10.1088/1742-2132/9/4/397.

[2] Culshaw, M. G., Jackson, P. D., and D. M. McCann (1987): Geophysical mapping techniques in environmental planning. In Culshaw MG, Bell FG, Cripps AC and O'Hara M (ed). Planning and Environmental Geology. Geological Society Special Publication 4, 171-177

[3] Roy, S. V. S., and N. L. Mohan (1984). Spectral interpretation of self-potential anomalies of some simple geometric bodies. PAGEOPH 78, $66-77$

[4] Atchuta Rao, D., H. V., Ram Babu (1983): Quantitative interpretation of self-potential anomalies due to two-dimensional sheet-like bodies. Geophysics 48, 1659 1664.

[5] Neal, A. (2004): Ground-penetrating radar and its use in sedimentology: principles, problems, and progress. Earth Science Review, 66, 261-330.

[6] Grasmueckm M. (1996): 3-D ground-penetrating radar applied to fracture imaging in gneiss. Geophysics 61, 1050-1064

[7] Davis, J. L. and A. P. Annan (1989): Ground penetrating radar for high-resolution mapping of soil and rocks stratigraphy. Geophysical Prospecting, 37, 531-551.

[8] Witten Technologies Inc. (2001): Final report- Pilot project, Large-scale underground utility mapping with ground-penetrating imaging radar, Witten Technologies Inc., 295 Huntington Avenue, Suite 203, Boston, MA 02115, USA.

[9] Oyawoye, M. O. (1964): The geology of the Nigerian basement complex. Journal of Nigerian Mining Geology and Metallurgical Society, 1, 87-482.

[10] Rahaman, M. A. (1976): Review of the Basement Geology of South-Western Nigeria. Geology of Nigeria (Kogbe, C. A. Ed.), Elizabethan Publishing Company, Nigeria, 41 -58.

[11] Rahaman, M. A., (1988): Recent advances in the study of the Basement Complex of Nigeria, In Precambrian Geology of Nigeria: Geological Survey of Nigeria, 11-41.

[12] Odeyemi, I. B. (1976): Preliminary report on the field relationships of Basement complex rocks around Igarra, Mid-Western State, Nigeria. In: Kogbe, C. A. ed. Geology of Nigeria, University of Ife.

[13] McCurry, P. (1976): The Geology of the Precambrian to Lower Paleozoic rocks of Northern Nigeria. In: Kogbe, C. A. ed. Geology of Ile-Ife, 15-39.

[14] Oyinloye, A. O. (2011): Geology and Geotectonic Setting of the Basement Complex Rocks in South Western Nigeria: Implications on Provenance and Evolution, Earth and Environmental Sciences, Dr. Imran Ahmad Dar (Ed.), ISBN: 978-953-307-468-9, InTech, Available from: http://www.intechopen.com/books/earthand-environmental-s ciences/geology-and-geotectonic-setting-of-the-basement-co mplex-rocks-in-southwestern-nigeria-implications-

[15] Adepelumi, A. A., Ako, B. D., and T. R. Ajayi (2001): Groundwater contamination in the basement-complex area of Ile-Ife, southwestern Nigeria: A case study using the electrical-resistivity geophysical method. Hydrogeology Journal, 9, 611-622.

[16] Olorunfemi, M. O., Olarewaju, V. O and M. Avci (1986): Geophysical investigation of a fault zone- Case history from Ile-Ife, Southwest Nigeria. Geophysical Prospecting 34 (8), $1277-1284$.

[17] Odeyemi I. (1981): A review of the orogenic events in the Precambrian basement of Nigeria, West Africa. Geologische Rundschau. 70 (3), 897 - 909.

[18] Ajibade, A. C., Woakes, M. and M. A. Rahaman (1987): Proterozoic crustal development in the Pan-African regime of Nigeria. Geodynamics Series, 17, $259-271$.

[19] Adepelumi, A. A., Ako, B. D., Ajayi, T. R., Olorunfemi, A. O., Awoyemi, M. O. and D. E. Falebita (2008): Integrated Geophysical mapping of the Ifewara transcurrent fault, Nigeria. Journal of African Earth sciences, 52 (4,5), 161-166.

[20] Riddihoug, R.P. (1971): Diurnal correction to magnetic survey - an assessment of errors. Geophysical Prospecting 19 (4), 551-567. 
[21] Breiner, S. (1999): Application manual for portable magnetometer. Geometrics, California, USA, pp. 1-58.

[22] Conyers, L. B., and D. Goodman (1997): Ground-Penetrating Radar: An Introduction for Archaeologists. Altamira Press, London.

[23] Adepelumi, A. A., Fayemi, O. and J. Akindulureni (2013): Geophysical Mapping of Subsurface Stratigraphy beneath a River Bed Using Ground Penetrating Radar: Lagos Nigeria Case Study. Universal Journal of Geoscience 1, 1, 10-19.

[24] Raju, D. Ch. V. (2003): LIMAT: a computer program for least-squares inversion of magnetic anomalies over long tabular bodies. Computers and Geosciences 29, 91-98.

[25] Asfahani, J., and M. Tlas (2004): Non-linearly constrained optimization theory to interpret magnetic anomalies due to vertical faults and thin dikes, Pure and Applied Geophysics, 161, 203-219.

[26] Abdelrahman, E. M., El-Arabi, H. M., Hassaneen, A. R. and M. A. Hafez (2003): New methods for shape and depth determinations from SP data, Geophysics, 68, 1202-1210.

[27] El-Araby, H. M. (2004): A new method for complete quantitative interpretation of self-potential anomalies. Journal of Applied Geophysics 55, 211 -224.

[28] Olorunfemi, M. O. and E T. Okhue (1992): Hydrogeological and geological significance of Geoelectrical survey at Ile-Ife, Nigeria. Journal of Mining and Geology. 28(2). 221-229

[29] Dojack, L. (2012): Ground Penetrating Radar Theory, Data Collection, Processing, and Interpretation: A Guide for Archaeologists. University of British Columbia Library, $1-92$. 